\title{
BMJ Open Diseases prevalent before major depressive disorder diagnosis: an exploratory nested case-control study using health insurance-based claims data
}

\author{
Yoshinori Cho (10 , ${ }^{1}$ Izumi Mishiro, ${ }^{2}$ Tsuyoshi Akaki, ${ }^{2}$ Takafumi Akimoto, ${ }^{2}$ \\ Keita Fujikawa ${ }^{2}$
}

To cite: Cho Y, Mishiro I, Akaki T, et al. Diseases prevalent before major depressive disorder diagnosis: an exploratory nested case-control study using health insurance-based claims data. BMJ Open 2022;12:e048233. doi:10.1136/ bmjopen-2020-048233

- Prepublication history and additional supplemental material for this paper are available online. To view these files, please visit the journal online (http://dx.doi.org/10.1136/ bmjopen-2020-048233).

Received 22 December 2020 Accepted 18 January 2022

Check for updates

(C) Author(s) (or their employer(s)) 2022. Re-use permitted under CC BY-NC. No commercial re-use. See rights and permissions. Published by BMJ.

${ }^{1}$ Department of Psychiatry, Teikyo University Mizonokuchi Hospital, Kawasaki, Kanagawa, Japan

2Japan Medical Office, Takeda Pharmaceutical Co Ltd, Tokyo, Japan

Correspondence to Dr Yoshinori Cho; yosinori@med.teikyo-u.ac.jp

\section{ABSTRACT}

Objectives Major depressive disorder (MDD) is often comorbid with other chronic and/or serious diseases. However, little is known about the prevalence of various diseases that are present before MDD onset. We examined the prevalence of all pre-existing diseases in the 12 months before an MDD diagnosis.

Design Exploratory nested case-control study.

Setting Data, including diagnoses based on International Statistical Classification of Diseases and Related Health Problems, 10th revision codes, were from a Japanese health insurance database (JMDC).

Participants Adults newly diagnosed with MDD during 2015, 2016 or 2017 (but not the preceding year) (cases) were matched (exact) 1:10 to controls by age, sex, index date and working status.

Primary and secondary outcome measures The primary outcome was the proportion of patients in each group with each pre-existing disease during the 12 months before the index date (ie, before MDD diagnosis in cases). Odds ratios (ORs) for onset of MDD were calculated for each pre-existing disease. A post hoc multivariate analysis examined interactions of metabolic risk factors (diabetes, hypertension, dyslipidaemia), psychiatric disorders (sleep disorders, psychiatric disorders other than depression) and MDD-related symptoms (headache, pain, autonomic nerve imbalance) on MDD diagnosis.

Results There were 13420 cases and 134200 controls (mean age 41.9 years; $66.5 \%$ male). The prevalence of almost all pre-existing diseases was higher in cases than in controls. The highest ORs (5.8-21.0) were for psychiatric diseases and sleep disorders. Insomnia (21.1\% of patients; OR 8.7) and neurosis $(9.7 \%$; OR 10.6) were particularly prevalent in the case group. The odds of MDD increased in the presence of metabolic risk factors, psychiatric disorders and/or MDD-related symptoms.

Conclusions There is a high prevalence of pre-existing diseases in Japanese patients who develop MDD compared with matched controls without MDD. These results suggest that patients with chronic and/or serious diseases should be actively monitored for depression.
Strengths and limitations of this study

- This is the first nested case-control study to examine a broad range of pre-existing diseases in people who develop major depressive disorder (MDD) compared with people who do not.

- The use of a nationwide health insurance database resulted in a sample size large enough to allow examination of less common pre-existing diseases.

- The nested case-control design and the use of a database minimised selection and recall biases that may occur in other case-control studies.

- Because of the nature of the database, the study did not include people aged $\geq 75$ years, and information on the physician making the MDD diagnosis was not available.

\section{INTRODUCTION}

Depression is frequently comorbid with other diseases, particularly chronic and/or serious diseases such as diabetes, cardiovascular/ cerebrovascular disease, cancer, asthma and arthritis. $^{1-3}$ The relationship between depression and most comorbidities is complex. For example, the temporal relationship appears to be bidirectional, in that depression can increase the risk of developing a chronic disease and vice versa. ${ }^{3}$ In addition, the relationship with depression varies with the type, duration and severity of disease, among other factors. ${ }^{1-3}$ Moreover, the presence of depression in patients with pre-existing diseases is associated with worse outcomes and quality of life, and possibly decreased survival. ${ }^{2}$ However, despite the accumulation of evidence for a link between depression and chronic illness, few studies have comprehensively compared the risk of depression in people with a broad range of pre-existing diseases. 
An epidemiological study conducted in Japan between 2013 and 2015 reported the lifetime and 12-month prevalence rates of major depressive disorder (MDD) to be relatively low, at $5.7 \%$ and $2.7 \%$, respectively. ${ }^{4}$ Other studies have confirmed that major depressive episodes are less prevalent in Japan than in other countries. ${ }^{56}$ However, fewer than half of Japanese people with a mood disorder seek medical treatment. ${ }^{4}$ This reluctance to seek medical treatment may be related to a perceived 'stigma' associated with psychiatric disease. ${ }^{7}$ These factors may further reduce the detection and diagnosis of MDD in patients with a chronic disease, despite the potentially increased risk of MDD in these patients. However, little is known about the prevalence of underlying diseases that are comorbid with MDD. Given that around 20000 people in Japan commit suicide every year, ${ }^{8}$ with the highest rate of about 50 per 100000 persons in men aged $50-59$ years, ${ }^{9}$ most of which are probably related to mental disorders, additional information on factors associated with MDD that could assist with early detection and treatment may help reduce the number of suicides.

The aim of this exploratory nested case-control study of patients enrolled in a Japanese health insurance database was to comprehensively examine the prevalence of pre-existing diseases in the 12 months before an MDD diagnosis (defined using the International Statistical Classification of Diseases and Related Health Problems, 10th revision (ICD-10) ${ }^{10}$ codes F32 ('Depressive episode') or F33 ('Recurrent depressive disorder')). In this context, a pre-existing disease was defined as any diagnosis other than MDD and related mental disorders (bipolar affective disorders; organic mental disorders; schizophrenia, schizotypal and delusional disorders); the latter were excluded to avoid including patients with secondary diagnoses of MDD as cases. However, our definition of preexisting conditions did include those that are prodromal symptoms of MDD (eg, sleep disorders), as well as psychiatric disorders that are less strongly linked to MDD. In addition, we determined an odds ratio (OR) for the onset of MDD for each pre-existing disease to identify those that are most commonly associated with development of MDD and to evaluate the association of MDD with common metabolic risk factors. We speculated that people with pre-existing diseases, including non-psychiatric diseases, might have an increased risk of subsequently developing MDD, which could be related to increased medical burden, shared underlying pathophysiological mechanisms or other reasons.

\section{METHODS}

\section{Study design and data source}

This was a nested case-control study. Data on patient demographics and diagnoses based on ICD-10 were derived from the JMDC (Tokyo, Japan) database of medical expense claims for company employees in Japan. $^{11}$

\section{Setting and participants}

The study analysed data collected for the population registered in the JMDC database between January 2014 and December 2018 who were aged $\geq 18$ years on 1 January of the inclusion year $(2015,2016$ or 2017) and had continuous registration for the inclusion year, the previous year and the subsequent year (study period). Individuals were excluded if they had a diagnosis of any bipolar affective disorder (ICD-10 codes F30 (manic episode), F31), organic mental disorder including symptomatic mental disorders (F00-F09), or schizophrenia, schizotypal and delusional disorder (F20-F29) in the study period, or a diagnosis of MDD (ICD-10 codes F32 ('Depressive episode') or F33 ('Recurrent depressive disorder')) in the year before the inclusion year, or no medical history for the year before the inclusion year.

Within the study population, case patients had a diagnosis of MDD in the inclusion year (the date of the first MDD treatment after $\geq 1$ year with no MDD diagnosis was designated as the index date) and $\geq 2$ months of treatment for depression within 90 days of the index date. Control patients had no diagnosis of MDD in the study period and were matched 10:1 (exact matching using random sampling) to case patients according to age at index date, sex and working status.

\section{Variables}

The primary end point was the proportion of patients with documented diagnosis of each pre-existing disease during the 12 months before the index date (ie, before MDD diagnosis in case patients). An OR for the onset of MDD was calculated for each underlying disease, which was based on presence or absence of ICD-10 codes, Charlson Comorbidity Index (CCI)-related diseases or other chronic diseases (online supplemental table 1). Demographic and patient characteristics were collected, including age, sex, working status and inclusion year (2015/2016/2017).

\section{Study size}

Sample size was determined by the number of cases and matched controls available in the database. Although a 4:1 matching ratio is generally considered to provide sufficient statistical power, the size of the database and the number of available controls allowed the ratio to be increased to $10: 1$.

\section{Statistical methods}

As noted above, the proportion of patients with each pre-existing disease was determined for each group and an OR for the onset of MDD was calculated. Prevalence data and ORs are reported for pre-existing diseases that were present in $\geq 1 \%$ of the case group and $\geq 0.1 \%$ of the control group. No inferential statistics were conducted. A post hoc analysis examined the possible interaction of the presence of three pre-existing disease categories that exhibited high ORs in the primary analysis or are common diseases: metabolic risk factors (diabetes, hypertension, 
dyslipidaemia), MDD-related symptoms (headache, pain, autonomic nerve imbalance), and psychiatric disorders (sleep disorders, psychiatric disorders other than depression) (online supplemental table 1). A multivariate logistic regression model was used to determine ORs in the eight subgroups (ie, with/without metabolic risk factors, MDD-related symptoms and/or psychiatric disease) for the onset of MDD using the following covariates: sex, age ( $<40$ years versus $\geq 40$ years) and working status. A similar post hoc analysis was conducted to estimate ORs for the onset of MDD according to the number of low risk ( $1 \leq \mathrm{OR} \leq 2$ in the primary analysis) CCI-related and other chronic diseases that were present during the preceding year. As above, sex, age and working status were adjusted for in the multivariate logistic regression model. Netezza N2002-010 7.1.0.4.P2 (IBM) was used as the data warehouse platform. SAS V.9.4 (SAS Institute) was used for statistical analysis.

\section{Patient and public involvement}

Patients and members of the public were not involved in the study.

\section{RESULTS}

\section{Participants}

From more than 6.5 million people enrolled in the JMDC database between 2014 and 2018, we identified 13420 case patients who met the inclusion criteria and had MDD diagnosed in 2015, 2016 or 2017 (case group; online supplemental figure). From 4212652 control patients who met the inclusion criteria and did not have an MDD diagnosis in either the inclusion year or the subsequent year, 134200 were matched to case patients (control group; online supplemental figure). More than half $(66.5 \%)$ of patients in both groups were male, with a mean age of 41.9 years (table 1 ). About $40 \%$ of patients were $<40$ years. Most $(77.8 \%)$ patients were workers.

\section{Prevalence of pre-existing diseases in the year before MDD diagnosis \\ CCl-related diseases and other chronic diseases}

The prevalence of almost all chronic diseases was higher in the case group than in the control group, with most ORs between 1.3 and 2.0 (table 2). The highest ORs were seen for attention deficit hyperkinetic disorders (OR 12.2), psychiatric diseases except depression (OR 9.9), dementia (OR 8.7, although prevalence was $\leq 0.1 \%$ in both groups), sleep disorders (OR 7.2) and autonomic nerve imbalance (OR 6.5). Of these, psychiatric diseases except depression and sleep disorders were highly prevalent in the case group ( $30.4 \%$ and $23.3 \%$, respectively). ORs $\geq 2.0$ were also observed (in descending order of prevalence in the case group) for pain (2.0), chronic gastritis (2.1), headache (2.7), peptic ulcer disease (2.0), dizziness (3.2), irritable bowel syndrome (3.2), angina pectoris (2.0), epilepsy (2.4), chronic enteritis (2.7), diabetes without chronic complication (2.1), metastatic
Table 1 Background and characteristics of case group

\begin{tabular}{ll}
\hline Variable & $\begin{array}{l}\text { Case group } \\
\mathbf{N}=13420\end{array}$ \\
\hline Male sex & $8924(66.5)$ \\
\hline Age & \\
\hline Mean (SD), years & $41.9(10.4)$ \\
\hline Median (range), years & $42.0(18-73)$ \\
\hline$<40$ years & $5390(40.2)$ \\
\hline W0 years & $8030(59.8)$ \\
\hline $\begin{array}{l}\text { Working status } \\
\text { Working }\end{array}$ & $10447(77.8)$ \\
\hline Non-working & $2973(22.2)$ \\
\hline Inclusion year & \\
\hline 2015 & $3853(28.7)$ \\
\hline 2016 & $4076(30.4)$ \\
\hline 2017 & $5491(40.9)$ \\
\hline $\begin{array}{l}\text { Number of beds in hospital where MDD was } \\
\text { diagnosed }\end{array}$ \\
\hline$<20$ & $10851(80.9)$ \\
\hline $\begin{array}{l}\text { Psychiatric facilities in hospital where MDD } \\
\text { was diagnosed }\end{array}$ & \\
\hline $\begin{array}{l}\text { Yes } \\
\text { No }\end{array}$ & $2569(19.1)$ \\
\hline
\end{tabular}

Data are $\mathrm{n}(\%)$, unless otherwise noted.

MDD, major depressive disorder; SD, standard deviation.

solid tumour (2.2), hemiplegia or paraplegia (2.8) and Parkinson's disease (3.2).

\section{ICD-10 blocks}

At the level of ICD-10 blocks, the prevalence of most preexisting diseases in the year before MDD diagnosis was slightly higher (OR 1.1-2.0) in the case group than in the control group (table 3). Exceptions were blocks O00-O99 and $\mathrm{P} 00-\mathrm{P} 96$, which are associated with pregnancy and/ or childbirth. However, the prevalence rates of mental and behavioural disorders (F00-F99) and diseases of the nervous system (G00-G99) were markedly higher in the case group, with ORs of 9.9 and 4.7, respectively. Among diseases of the circulatory system (I00-I99), respiratory system (J00-J99) and digestive system (K00-K93), the OR for digestive diseases was the highest (2.0 for digestive vs 1.6 for circulatory and respiratory). The OR for diseases of the eye and adnexa (H00-H59) was low (1.1), whereas the OR for diseases of the ear and mastoid process (H60H95) was relatively high (1.8).

\section{ICD-10 codes}

As with the ICD-10 blocks, the prevalence of almost all pre-existing diseases based on three- or four-character ICD-10 codes in the year before MDD diagnosis was slightly higher in the case group than in the control group 
Table 2 Prevalence of pre-existing diseases, ranked by prevalence in the case group

\begin{tabular}{|c|c|c|c|}
\hline Disease & $\begin{array}{l}\text { Case group } \\
\mathrm{N}=13420\end{array}$ & $\begin{array}{l}\text { Matched control group } \\
N=134200\end{array}$ & OR (95\% Cl) \\
\hline \multicolumn{4}{|l|}{$\mathrm{CCl}$-related diseases } \\
\hline Peptic ulcer disease & $1431(10.7)$ & $7659(5.7)$ & 2.0 (1.9 to 2.1$)$ \\
\hline Mild liver disease & $1392(10.4)$ & $9336(7.0)$ & 1.5 (1.5 to 1.6$)$ \\
\hline Chronic pulmonary disease (exc. asthma) & $973(7.3)$ & $7381(5.5)$ & $1.3(1.3$ to 1.4$)$ \\
\hline Cerebrovascular disease & $448(3.3)$ & $2378(1.8)$ & $1.9(1.7$ to 2.1$)$ \\
\hline Peripheral vascular disease & $359(2.7)$ & $2237(1.7)$ & $1.6(1.4$ to 1.8$)$ \\
\hline Congestive heart failure & 347 (2.6) & $1885(1.4)$ & $1.9(1.7$ to 2.1$)$ \\
\hline Second solid tumour (non-metastatic) & $327(2.4)$ & $2357(1.8)$ & $1.4(1.2$ to 1.6$)$ \\
\hline Diabetes with chronic complication & $239(1.8)$ & $1758(1.3)$ & $1.4(1.2$ to 1.6$)$ \\
\hline Rheumatic disease & $192(1.4)$ & $1066(0.8)$ & 1.8 (1.6 to 2.1$)$ \\
\hline Diabetes without chronic complication & $107(0.8)$ & $502(0.4)$ & 2.1 (1.7 to 2.6$)$ \\
\hline Renal disease & $77(0.6)$ & $708(0.5)$ & 1.1 (0.9 to 1.4$)$ \\
\hline Metastatic solid tumour & $52(0.4)$ & $241(0.2)$ & 2.2 (1.6 to 2.9$)$ \\
\hline Myocardial infarction & $46(0.3)$ & $338(0.3)$ & $1.4(1.0$ to 1.9$)$ \\
\hline Hemiplegia or paraplegia & $39(0.3)$ & $138(0.1)$ & 2.8 (2.0 to 4.0$)$ \\
\hline Lymphoma/multiple myeloma & $25(0.2)$ & $174(0.1)$ & 1.4 (0.9 to 2.2$)$ \\
\hline Dementia & $13(0.1)$ & $15(<0.1)$ & 8.7 (4.1 to 18.2$)$ \\
\hline Leukaemia & $9(0.1)$ & $97(0.1)$ & $0.9(0.5$ to 1.8$)$ \\
\hline Moderate or severe liver disease & $7(0.1)$ & $54(<0.1)$ & $1.3(0.6$ to 2.8$)$ \\
\hline \multicolumn{4}{|l|}{ Other chronic diseases } \\
\hline Pain & $4598(34.3)$ & $27452(20.5)$ & $2.0(2.0$ to 2.1$)$ \\
\hline Psychiatric diseases except depression & $4084(30.4)$ & $5691(4.2)$ & 9.9 (9.4 to 10.3$)$ \\
\hline Sleep disorders & $3128(23.3)$ & $5462(4.1)$ & $7.2(6.8$ to 7.5$)$ \\
\hline Chronic gastritis & $2349(17.5)$ & $12568(9.4)$ & 2.1 (2.0 to 2.2 ) \\
\hline Dyslipidaemia & $2286(17.0)$ & $17438(13.0)$ & $1.4(1.3$ to 1.4$)$ \\
\hline Headache & $2129(15.9)$ & $8634(6.4)$ & 2.7 (2.6 to 2.9 ) \\
\hline Hypertensive disease & $1987(14.8)$ & $15052(11.2)$ & $1.4(1.3$ to 1.4$)$ \\
\hline Asthma & $1861(13.9)$ & $12923(9.6)$ & $1.5(1.4$ to 1.6$)$ \\
\hline Dizziness & $1309(9.8)$ & $4345(3.2)$ & $3.2(3.0$ to 3.4$)$ \\
\hline Arthritis & $729(5.4)$ & $5217(3.9)$ & 1.4 (1.3 to 1.5$)$ \\
\hline Osteoarthritis & $654(4.9)$ & $4290(3.2)$ & $1.6(1.4$ to 1.7$)$ \\
\hline Atopic dermatitis & $608(4.5)$ & $5984(4.5)$ & $1.0(0.9$ to 1.1$)$ \\
\hline Irritable bowel syndrome & $588(4.4)$ & $1900(1.4)$ & $3.2(2.9$ to 3.5$)$ \\
\hline Thyroid disease & $551(4.1)$ & $3394(2.5)$ & 1.7 (1.5 to 1.8$)$ \\
\hline Autonomic nerve imbalance & 409 (3.0) & $647(0.5)$ & 6.5 (5.7 to 7.4$)$ \\
\hline Angina pectoris & 405 (3.0) & $2058(1.5)$ & 2.0 (1.8 to 2.2$)$ \\
\hline Osteoporosis & $226(1.7)$ & $1611(1.2)$ & $1.4(1.2$ to 1.6$)$ \\
\hline Epilepsy & $177(1.3)$ & $729(0.5)$ & 2.4 (2.1 to 2.9$)$ \\
\hline Chronic enteritis & $153(1.1)$ & $561(0.4)$ & 2.7 (2.3 to 3.3 ) \\
\hline Obesity & $74(0.6)$ & $513(0.4)$ & $1.4(1.1$ to 1.8$)$ \\
\hline Attention deficit hyperkinetic disorders & $56(0.4)$ & $46(<0.1)$ & $12.2(8.3$ to 18.1$)$ \\
\hline Parkinson's disease & $24(0.2)$ & $76(0.1)$ & $3.2(2.0$ to 5.0$)$ \\
\hline
\end{tabular}

The prevalence of $\mathrm{CCl}$-related diseases and other chronic diseases in the 12 months before the index date in the case group and matched control group is shown ranked by prevalence in the case group. Data are $\mathrm{n}(\%)$, unless otherwise noted.

$\mathrm{CCl}$, Charlson Comorbidity Index; $\mathrm{Cl}$, confidence interval; exc., excluding; OR, odds ratio. 
Table 3 Prevalence of pre-existing diseases in the case group and matched control group by ICD-10 block

\begin{tabular}{|c|c|c|c|c|}
\hline ICD-10 block & ICD-10 block name & $\begin{array}{l}\text { Case group } \\
\mathrm{N}=13420\end{array}$ & $\begin{array}{l}\text { Matched } \\
\text { control group } \\
\mathrm{N}=134200\end{array}$ & OR $(95 \% \mathrm{Cl})$ \\
\hline A00-B99 & Certain infectious and parasitic diseases & $4583(34.2)$ & $33852(25.2)$ & $1.5(1.5$ to 1.6$)$ \\
\hline C00-D48 & Neoplasms & $1575(11.7)$ & $12007(8.9)$ & $1.4(1.3$ to 1.4$)$ \\
\hline D50-D89 & $\begin{array}{l}\text { Diseases of the blood and blood-forming organs and } \\
\text { certain disorders involving the immune mechanism }\end{array}$ & $1041(7.8)$ & $7612(5.7)$ & $1.4(1.3$ to 1.5$)$ \\
\hline E00-E90 & Endocrine, nutritional and metabolic diseases & $4477(33.4)$ & $32630(24.3)$ & $1.6(1.5$ to 1.6$)$ \\
\hline F00-F99 & Mental and behavioural disorders & $4084(30.4)$ & $5691(4.2)$ & 9.9 (9.4 to 10.3$)$ \\
\hline G00-G99 & Diseases of the nervous system & $4965(37.0)$ & $14847(11.1)$ & $4.7(4.5$ to 4.9$)$ \\
\hline $\mathrm{H} 00-\mathrm{H} 59$ & Diseases of the eye and adnexa & $5035(37.5)$ & 46365 (34.5) & $1.1(1.1$ to 1.2$)$ \\
\hline H60-H95 & Diseases of the ear and mastoid process & $1735(12.9)$ & $10245(7.6)$ & $1.8(1.7$ to 1.9$)$ \\
\hline $100-199$ & Diseases of the circulatory system & $3038(22.6)$ & 20545 (15.3) & $1.6(1.6$ to 1.7$)$ \\
\hline J00-J99 & Diseases of the respiratory system & $9232(68.8)$ & $77686(57.9)$ & $1.6(1.5$ to 1.7$)$ \\
\hline K00-K93 & Diseases of the digestive system & $7015(52.3)$ & $47838(35.6)$ & 2.0 (1.9 to 2.0$)$ \\
\hline L00-L99 & Diseases of the skin and subcutaneous tissue & $4428(33.0)$ & $37648(28.1)$ & $1.3(1.2$ to 1.3$)$ \\
\hline M00-M99 & $\begin{array}{l}\text { Diseases of the musculoskeletal system and } \\
\text { connective tissue }\end{array}$ & $5322(39.7)$ & $35387(26.4)$ & $1.8(1.8$ to 1.9$)$ \\
\hline N00-N99 & Diseases of the genitourinary system & $2880(21.5)$ & $20016(14.9)$ & $1.6(1.5$ to 1.6$)$ \\
\hline O00-099 & Pregnancy, childbirth and the puerperium & $178(1.3)$ & $2944(2.2)$ & $0.6(0.5$ to 0.7$)$ \\
\hline P00-P96 & Certain conditions originating in the perinatal period & $19(0.1)$ & $212(0.2)$ & $0.9(0.6$ to 1.4$)$ \\
\hline Q00-Q99 & $\begin{array}{l}\text { Congenital malformations, deformations and } \\
\text { chromosomal abnormalities }\end{array}$ & $199(1.5)$ & $1496(1.1)$ & $1.3(1.2$ to 1.5$)$ \\
\hline R00-R99 & $\begin{array}{l}\text { Symptoms, signs and abnormal clinical and laboratory } \\
\text { findings, not elsewhere classified }\end{array}$ & $5241(39.1)$ & $28989(21.6)$ & $2.3(2.2$ to 2.4$)$ \\
\hline S00-T98 & $\begin{array}{l}\text { Injury, poisoning and certain other consequences of } \\
\text { external causes }\end{array}$ & $2209(16.5)$ & $17661(13.2)$ & $1.3(1.2$ to 1.4$)$ \\
\hline Z00-Z99 & $\begin{array}{l}\text { Factors influencing health status and contact with } \\
\text { health services }\end{array}$ & $252(1.9)$ & $1878(1.4)$ & $1.3(1.2$ to 1.5$)$ \\
\hline U00-U99 & Codes for special purposes & $0(0)$ & $1(<0.1)$ & NE \\
\hline
\end{tabular}

Data are $\mathrm{n}(\%)$, unless otherwise noted.

$\mathrm{Cl}$, confidence interval; ICD-10, International Statistical Classification of Diseases and Related Health Problems, 10th revision; NE, not estimable; OR, odds ratio.

(figure 1; online supplemental table 2). The highest ORs for the onset of MDD were observed for psychiatric diseases and sleep disorders (figure 1 ). ORs $>5$ were seen for adjustment disorders, panic disorder, anxiety disorder, depressive neurosis, neurosis, insomnia, psychosomatic disorder, anxiety, sleeping disorder, autonomic ataxia and palpitations. Of these comorbidities, insomnia and neurosis were particularly prevalent in the case group (21.1\% and $9.7 \%$ of patients, respectively).

Multivariate analysis

A post hoc multivariate analysis indicated that the odds of developing MDD were lower in women than in men, in patients $\geq 40$ years than in younger patients and in non-workers than in workers (table 4). The odds of MDD also increased in subgroups with metabolic risk factors, psychiatric disorders and/or MDD-related symptoms, relative to 84763 individuals without any of these diseases (online supplemental table 3). The highest ORs $(>10)$ were seen in subgroups with psychiatric disorders. Compared with subgroups with MDD-related symptoms only, the odds of MDD were increased in subgroups who also had metabolic risk factors or psychiatric disorders. However, the odds of MDD decreased in subgroups who had both metabolic risk factors and psychiatric disorders relative to subgroups with only one of these factors (with or without MDD-related symptoms). Finally, we identified 72923 people (8329 cases with MDD and 64594 controls) who had at least one low-risk $(1 \leq \mathrm{OR} \leq 2)$ pre-existing CCIrelated or other chronic disease (table 2 ) and categorised them based on the number of diseases from one $(\mathrm{N}=36$ 993) to 11-13 ( $\mathrm{N}=46)$. Relative to people with only one pre-existing disease, the OR for MDD increased with the number of pre-existing chronic diseases, from 1.34 in people with two pre-existing diseases to more than 
A
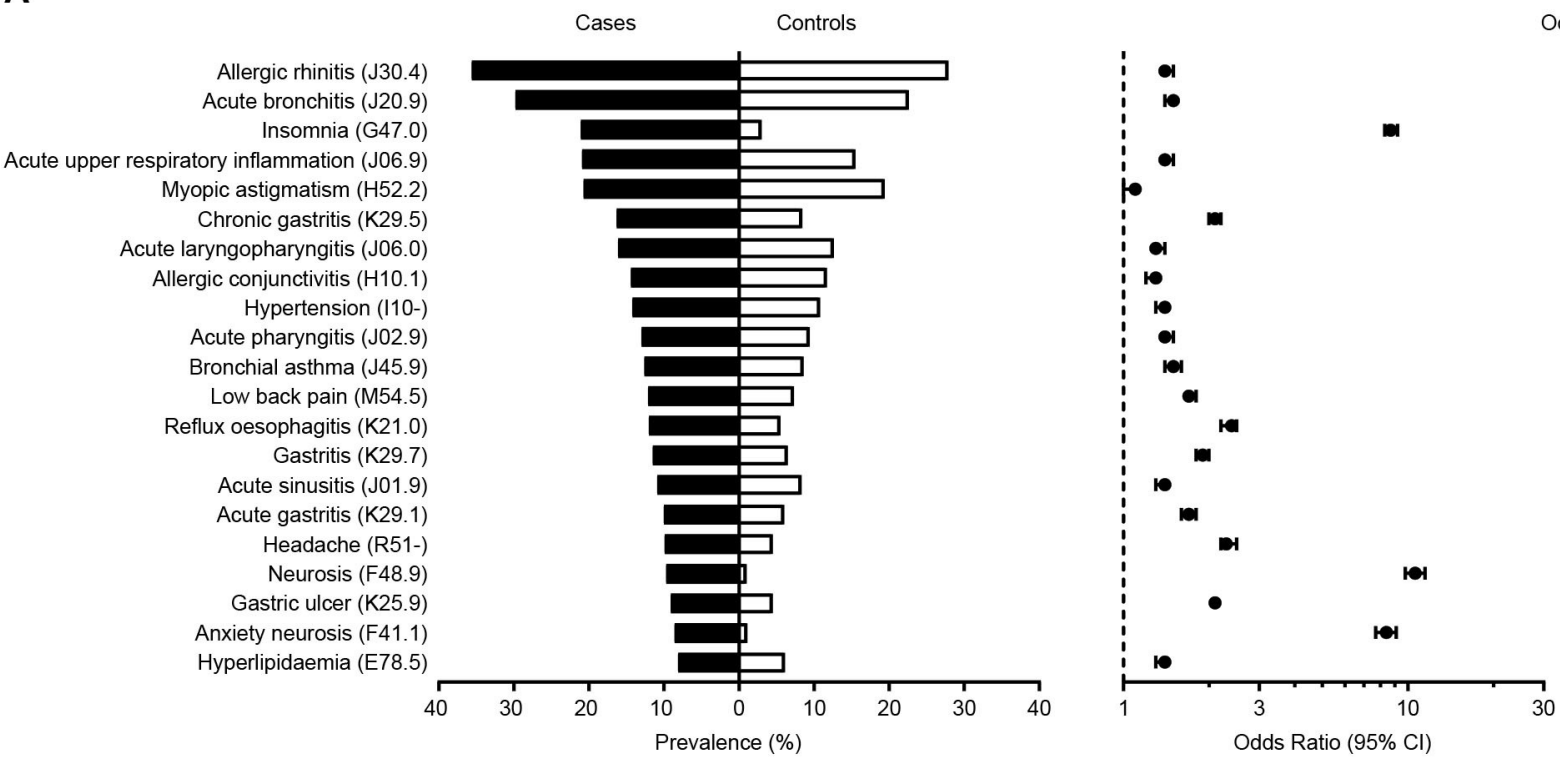

Odds Ratio (95\% Cl)

$1.4(1.4-1.5)$

$1.5(1.4-1.5)$

$8.7(8.3-9.2)$

$1.4(1.4-1.5)$

$1.1(1.0-1.1)$

$2.1(2.0-2.2)$

$1.3(1.3-1.4)$

$1.3(1.2-1.3)$

$1.4(1.3-1.4)$

$1.4(1.4-1.5)$

$1.5(1.4-1.6)$

$1.7(1.7-1.8)$

$2.4(2.2-2.5)$

$1.9(1.8-2.0)$

$1.4(1.3-1.4)$

$1.7(1.6-1.8)$

$2.3(2.2-2.5)$

$10.6(9.8-11.5)$

$2.1(2.0-2.2)$

$8.4(7.7-9.1)$

$1.4(1.3-1.4)$

B
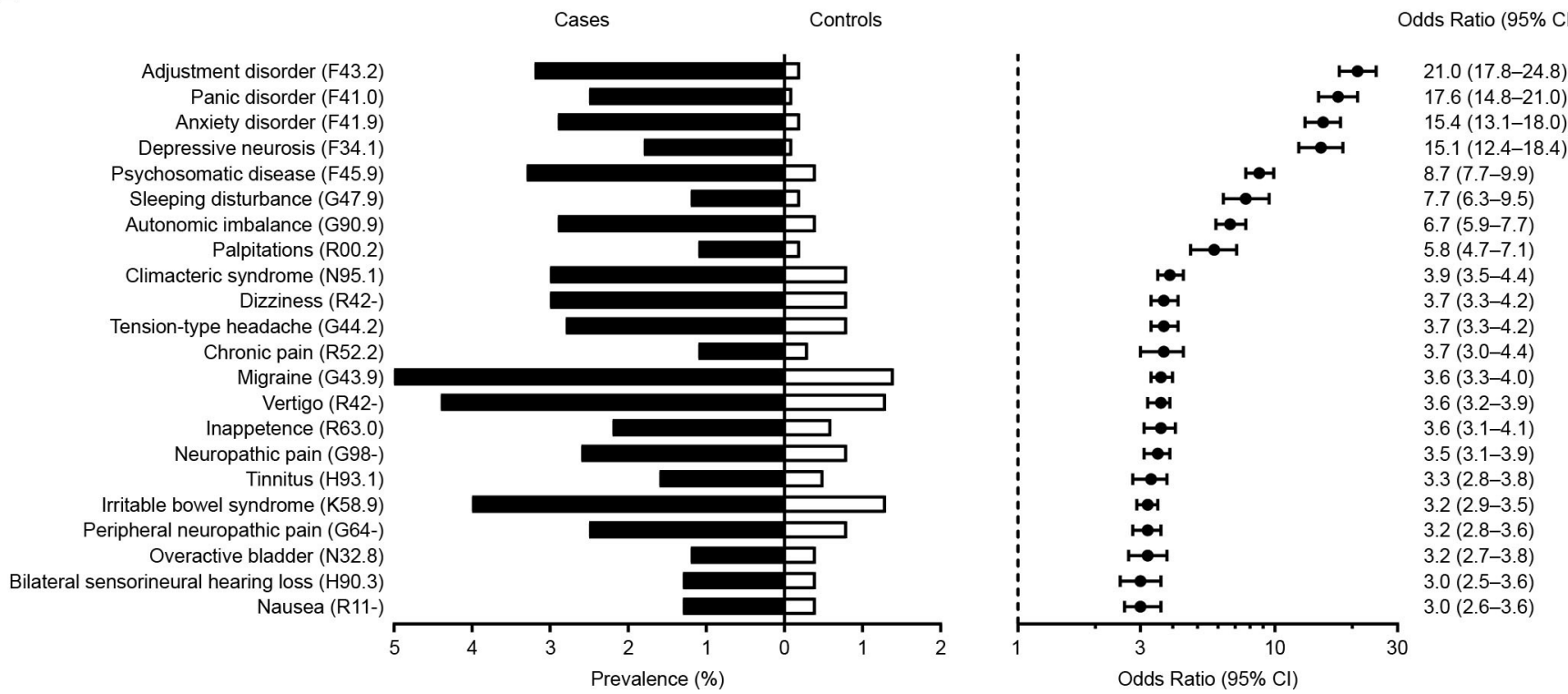

Figure 1 (A) Diseases with prevalence $>8 \%$ in the case group in the 12 months before MDD diagnosis. (B) Diseases with $\mathrm{OR}>3$.0. Shown are the prevalence rates in the case group and in the matched control group, as well as the $\mathrm{OR}(95 \% \mathrm{Cl})$. $\mathrm{Cl}$, confidence interval; MDD, major depressive disorder; OR, odds ratio.

three in people with nine or more comorbidities (online supplemental table 4).

\section{DISCUSSION}

This is the first nested case-control study to demonstrate that a broad range of pre-existing diseases are more prevalent in people who develop MDD than in those who do not. These results indicate that most patients have complex health conditions before starting treatment for MDD. The highest ORs were seen for sleep disorders and psychiatric diseases other than depression, which were also among the most prevalent pre-existing diseases in the case group. Other common diseases that were more prevalent in the case group included pain, headache, autonomic disturbances, gastrointestinal diseases and metabolic risk factors, such as dyslipidaemia, hypertension and diabetes.

Our results support and extend the results of previous studies reporting a high prevalence of pre-existing or comorbid diseases in patients with depression. Most previous studies have been cross-sectional or small case-control studies focused on specific comorbid diseases. $^{2312-15}$ Two large case-control studies conducted in the USA, using electronic health records at the Mayo Clinic $^{16}$ and South Korea, using the National Health Insurance Service, ${ }^{17}$ identified pre-existing chronic 
Table 4 Multivariate logistic regression analysis for the onset of MDD

\begin{tabular}{|c|c|c|c|c|c|c|}
\hline Dependent variable & Explanatory variable & Reference & Category & & & OR $(95 \% \mathrm{Cl})$ \\
\hline \multirow{7}{*}{$\begin{array}{l}\text { Group } \\
\text { (reference=control } \\
\text { group) }\end{array}$} & Sex & Male & Female & & & 0.93 (0.89 to 0.98$)$ \\
\hline & Age & $<40$ years & $\geq 40$ years & & & 0.80 (0.77 to 0.83$)$ \\
\hline & \multirow{5}{*}{$\begin{array}{l}\text { Presence of metabolic } \\
\text { risk factor, psychiatric } \\
\text { disorder and/or MDD- } \\
\text { related symptoms } \\
\text { during the } 12 \text { months } \\
\text { before index date }\end{array}$} & \multirow[t]{5}{*}{ None } & $\begin{array}{l}\text { Metabolic risk } \\
\text { factor }\end{array}$ & $\begin{array}{l}\text { Psychiatric } \\
\text { disorder }\end{array}$ & $\begin{array}{l}\text { MDD-related } \\
\text { symptoms }\end{array}$ & \\
\hline & & & No & Yes & Yes & $13.47(12.54$ to 14.47$)$ \\
\hline & & & Yes & No & No & 1.14 (1.06 to 1.23$)$ \\
\hline & & & Yes & No & Yes & 2.27 (2.10 to 2.46$)$ \\
\hline & & & Yes & Yes & No & 7.27 (6.61 to 7.99$)$ \\
\hline
\end{tabular}

'Metabolic risk factors' included diabetes, hypertension and dyslipidaemia; 'psychiatric disorders' included sleep disorders and psychiatric diseases other than depression; 'MDD-related symptoms' included headache, pain and autonomic nerve imbalance (online supplemental table 1).

$\mathrm{Cl}$, confidence interval; MDD, major depressive disorder; OR, odds ratio.

physical conditions that were risk factors for the development of MDD. However, these studies focused on a smaller number (24 and 19) of specific chronic conditions compared with our study, which examined a broad range of both chronic and acute conditions.

Stress, such as diagnosis with a chronic or serious disease, can contribute to the development of MDD in vulnerable individuals. ${ }^{18}$ Further, stress can lead to psychological and physiological changes that affect both mental and physical health, and may contribute directly to depression. ${ }^{19}$ Psychiatric disorders can be particularly stressful and may increase the chances of MDD. Depression is often comorbid with other mental disorders, particularly anxiety, and may share symptoms and underlying aetiologies. ${ }^{20-23}$ Our results support this link and further suggest that depression may be present in patients with other psychiatric disorders but may not be diagnosed as MDD until symptoms become severe. Stress is also associated with many gastrointestinal disorders, ${ }^{24}$ such as irritable bowel syndrome, which were twice as prevalent in the case group than in the control group.

Depression-related symptoms (sleep disorders, pain, autonomic imbalance) may be diagnosed in advance of MDD and therefore may be prodromal symptoms of MDD. ${ }^{25}$ Somatic symptoms of MDD, such as fatigue, appetite loss, pain (especially headache), dizziness and sleep disturbance, can be non-specific and may be attributed to physical illness. ${ }^{26}$ Indeed, a significant proportion of patients with MDD present with only somatic symptoms. ${ }^{27}$ One reason is denial of psychological symptoms, which is particularly prevalent in Japan. ${ }^{27}$ These results support the idea that depression is under-recognised when patients first seek medical help in Japan, and also support our findings that digestive diseases, sleep disorders and other somatic symptoms, including in the otological area (eg, dizziness), were highly prevalent in patients who later developed MDD. Interestingly, we observed that the OR for diseases of the ear and mastoid process was higher than for diseases of the eye and adnexa (1.8 vs 1.1). We suggest that physicians in otolaryngology departments may be aware of the link between somatic symptoms and MDD and consider psychological evaluation for patients with such symptoms. In contrast, physicians in ophthalmology departments may need to pay more attention to the risk of MDD in patients with severe visual dysfunction because both hearing loss and vision loss are associated with the development of depression. ${ }^{28}$

Our multivariate analysis indicated that the odds of an MDD diagnosis were increased in patients who had depression-related symptoms (headache, pain, autonomic imbalance), particularly if the patient also had a sleep/psychiatric disorder or metabolic risk factor. Interestingly, the odds of MDD decreased in subgroups with metabolic risk factors in addition to psychiatric disorders. Although the reason for this finding is unclear, it may be that these patients are managed by multiple physicians who focus on treating each disease separately (eg, psychiatrist treating psychiatric diseases; general practitioner treating metabolic risk factors), with the result that MDD is not sufficiently recognised. Indeed, some general practitioners and other non-psychiatrist doctors in Japan fail to recognise or are reluctant to treat MDD, ${ }^{29}{ }^{30}$ which may contribute to underdiagnosis of MDD in patients with metabolic risk factors. Psychiatrists, on the other hand, may underestimate somatic depressive symptoms in patients they are treating for another mental illness who also have a metabolic-related illness treated by another doctor, considering fatigue and autonomic dysfunction as caused by the physical illness. However, depression is known to lead to treatment non-adherence in patients with diabetes, ${ }^{31}$ which increases the risk of severe complications. ${ }^{32}$ In addition, treating metabolic-related diseases 
and depression simultaneously may provide patients with better clinical outcomes. ${ }^{33}$ Further research is needed on the unmet needs for the diagnosis and treatment of depression in patients with presymptomatic depression in addition to metabolic-related diseases, and on the effects of coordinated care management of multiple conditions.

We also found that the risk of MDD increased with increasing number of relatively low-risk (OR $\leq 2)$ CCIrelated and other chronic diseases. Thus, increased medical burden appears to be associated with greater risk of depression among working-age people, consistent with a recent study conducted in Denmark. ${ }^{34}$

Many comorbidities may share underlying biological mechanisms with MDD. For example, inflammatory mechanisms play a role in the aetiology of many diseases, including diabetes, cardiovascular disease, arthritis and asthma, as well as, depression. ${ }^{35-37}$ Neural pathways and neurotransmitters that are altered in chronic pain may also affect mood, including depression. ${ }^{38}$ Migraine and depression can both be related to specific genetic variants and/or neuroanatomic features. ${ }^{39}$ Most of these biological mechanisms are exacerbated by stress. ${ }^{3} 36$ Thus, MDD may develop in parallel with certain diseases, but its diagnosis may be delayed compared with physical disease.

\section{Strengths and limitations}

Our study is strengthened by the use of a health insurance database consisting of mostly working-age people, which resulted in a sample size large enough to allow examination of a broad range of pre-existing diseases. The nested case-control design and the use of a database minimised selection and recall biases that may occur in other case-control studies. We used a strict definition of MDD onset, which required a 1-year depression-free period and the diagnosis for inclusion to be recorded on at least three doctor visits within 90 days; this definition increased our certainty that case patients had true, newly diagnosed MDD. In addition, our inclusion criteria meant that people in both the control and case groups needed to have visited a doctor at least once to have a medical record within the observation period. Because of the comprehensive insurance available in Japan, medical care is readily accessible and consultations for relatively minor concerns are common. Therefore, the controls in our study can essentially be considered as representative of the general population, except for the absence of people aged 75 years or older, who are covered by governmentadministered insurance, and the relatively low proportion of people aged 65-74 years, many of whom would be retired from work.

Despite these strengths, some caveats do apply when interpreting our results. As with any claims database study, the data were not collected specifically for the purpose of the study. As such, we could not evaluate variables like socioeconomic factors or severity/ history of MDD. Further, errors in ICD-10 coding may have occurred, although equally in cases and controls. Patients with chronic diseases are likely to visit their physicians frequently, increasing the opportunity for detection and diagnosis of MDD. Further, patients with pre-existing psychiatric disorders are likely to be treated by psychiatrists, who may be better at diagnosing MDD than other physicians, which might lead to higher ORs for psychiatric diseases than for physical diseases; however, MDD diagnosis by general practitioners is also higher in patients with psychiatric comorbidity than in those with physical comorbidity. ${ }^{40}$ Nevertheless, MDD is often under-recognised and underdiagnosed, which may mean that the control group included patients who actually had depression or depressive symptoms. We only assessed disease prevalence, and not incidence, during the year before the inclusion year; therefore, we do not know if the disease was diagnosed during that year or in a previous year. This limitation could potentially result in a disproportionate number of people in the control group who had longer-term diseases and were not vulnerable to MDD. For some high-stress diseases such as cancer or stroke, MDD often occurs soon after diagnosis ${ }^{41}{ }^{42}$; hence, less vulnerable patients who did not develop MDD would have remained within the control group, leading to lower ORs for those diseases than might be expected. Further, the nature of the database made it difficult to exclude patients with an MDD diagnosis more than a year previously; consequently, our cases could have included patients with recurrent MDD as well as those diagnosed for the first time. The use of standard logistic regression instead of conditional logistic regression may also have resulted in the underestimation of ORs. Finally, the relatively short observation period limits our ability to look at the long-term relationship between MDD, which can reoccur multiple times in a patient's life, and other chronic conditions. Although comparing ORs for the onset of MDD across a broad range of pre-existing diseases can help develop hypotheses regarding possible underlying mechanisms, the risk of MDD occurring in specific diseases should be investigated on an individual basis.

\section{Conclusions}

This large, preliminary, nested case-control study has documented the high prevalence of pre-existing diseases in Japanese patients with MDD compared with matched controls without MDD. The high prevalence of preexisting diseases in patients who develop MDD reflects the complex relationship between physical and mental disorders and indicates a high medical burden for these patients. These results confirm that patients with chronic and/or serious diseases, including prodromal symptoms that are not always recognised as related to MDD, should be monitored for depressive symptoms and preexisting diseases should be taken into consideration when prescribing treatment for MDD.

Acknowledgements The authors would like to thank Chie Ito, MS and Yuki Otaka, BS, of the Data Solution Division, JMDC, for database construction and statistical analysis assistance, which were funded by Takeda. Medical writing assistance was provided by Rebecca Lew, PhD, CMPP and Serina Stretton, PhD, CMPP, of 
ProScribe-Envision Pharma Group, and was funded by Takeda. ProScribe's services complied with international guidelines for Good Publication Practice (GPP3).

Contributors YC designed the study and data collection, interpreted the study results, participated in the drafting, critical revision and approval of the final version of the manuscript, and will act as guarantor. IM designed the study and data collection, wrote the statistical analysis plan, interpreted the study results and participated in the drafting, critical revision, and approval of the final version of the manuscript. TsA designed the study and data collection, interpreted the study results, and participated in the drafting, critical revision and approval of the final version of the manuscript. TaA designed the study and data collection, interpreted the study results, and participated in the drafting, critical revision, and approval of the final version of the manuscript. KF designed the study and data collection, interpreted the study results, and participated in the drafting, critical revision and approval of the final version of the manuscript.

Funding This work was supported by Takeda Pharmaceutical Company, manufacturer/licensee of vortioxetine in the USA and Japan in alliance with Lundbeck AS. Takeda Pharmaceutical Company was involved in the study design, data collection, data analysis, preparation of the manuscript, and decision to submit the manuscript for publication.

Competing interests $\mathrm{YC}$ reports grants from Shionogi \& $\mathrm{Co}$ and Otsuka Pharmaceutical, and personal fees from Shionogi \& Co, Otsuka Pharmaceutical Co, Eli Lilly Japan K.K., Kyowa Kirin Co, Pfizer Japan, Meiji Seika Pharma, Mitsubishi Tanabe Pharma, Sumitomo Dainippon Pharma Co, Astellas Pharma, MSD K.K., Takeda Pharmaceutical Company, and Lundbeck Japan K.K., outside the submitted work. IM, TsA, TaA and KF report personal fees from Takeda Pharmaceutical Company, outside the submitted work.

\section{Patient consent for publication Not applicable.}

Ethics approval The study was approved by the Ethics Review Committee of the Research Institute of Healthcare Data Science (Tokyo, Japan) on 6 August 2019 (approval number RI2019004). Only anonymised information was accessible from the database; therefore, in accordance with the Ethical Guidelines for Medical and Health Research Involving Human Subjects in Japan, informed consent was not required.

Provenance and peer review Not commissioned; externally peer reviewed.

Data availability statement Data may be obtained from a third party and are not publicly available. The data that support the findings of this study are available from JMDC but were used under licence for the current study; therefore, restrictions apply and the data are not publicly available. For inquiries about access to the data set used in this study, please contact JMDC (https://www.jmdc.co.jp).

Supplemental material This content has been supplied by the author(s). It has not been vetted by BMJ Publishing Group Limited (BMJ) and may not have been peer-reviewed. Any opinions or recommendations discussed are solely those of the author(s) and are not endorsed by BMJ. BMJ disclaims all liability and responsibility arising from any reliance placed on the content. Where the content includes any translated material, BMJ does not warrant the accuracy and reliability of the translations (including but not limited to local regulations, clinical guidelines, terminology, drug names and drug dosages), and is not responsible for any error and/or omissions arising from translation and adaptation or otherwise.

Open access This is an open access article distributed in accordance with the Creative Commons Attribution Non Commercial (CC BY-NC 4.0) license, which permits others to distribute, remix, adapt, build upon this work non-commercially, and license their derivative works on different terms, provided the original work is properly cited, appropriate credit is given, any changes made indicated, and the use is non-commercial. See: http://creativecommons.org/licenses/by-nc/4.0/.

ORCID iD

Yoshinori Cho http://orcid.org/0000-0003-0780-6587

\section{REFERENCES}

1 Clarke DM, Currie KC. Depression, anxiety and their relationship with chronic diseases: a review of the epidemiology, risk and treatment evidence. Med J Aust 2009;190:S54-60.

2 Evans DL, Charney DS, Lewis L, et al. Mood disorders in the medically ill: scientific review and recommendations. Biol Psychiatry 2005;58:175-89.
3 Katon WJ. Epidemiology and treatment of depression in patients with chronic medical illness. Dialogues Clin Neurosci 2011;13:7-23.

4 Ishikawa $\mathrm{H}$, Tachimori $\mathrm{H}$, Takeshima T, et al. Prevalence, treatment, and the correlates of common mental disorders in the mid 2010's in Japan: the results of the World Mental Health Japan 2nd survey. $J$ Affect Disord 2018;241:554-62.

5 Andrade L, Caraveo-Anduaga JJ, Berglund P, et al. The epidemiology of major depressive episodes: results from the International Consortium of Psychiatric Epidemiology (ICPE) surveys. Int $\mathrm{J}$ Methods Psychiatr Res 2003;12:3-21.

6 Bromet E, Andrade LH, Hwang I, et al. Cross-national epidemiology of DSM-IV major depressive episode. BMC Med 2011;9:90.

7 Ando S, Yamaguchi S, Aoki Y, et al. Review of mental-health-related stigma in Japan. Psychiatry Clin Neurosci 2013;67:471-82.

8 Ministry of Health, Labour and Welfare. Vital statistics of Japan, 2017. Available: https://www.mhlw.go.jp/english/database/db-hw/dl/ 81-1a2en.pdf [Accessed 16 Jan 2020].

9 Snowdon J, Phillips J, Zhong B, et al. Changes in age patterns of suicide in Australia, the United States, Japan and Hong Kong. J Affect Disord 2017;211:12-19.

10 International statistical classification of diseases and related health problems, 10th revision, 2016. Available: https://icd.who.int/ browse10/2016/en [Accessed 16 Jan 2020].

11 Kimura S, Sato T, Ikeda S, et al. Development of a database of health insurance claims: standardization of disease classifications and anonymous record linkage. J Epidemiol 2010;20:413-9.

12 Daré LO, Bruand P-E, Gérard D, et al. Co-morbidities of mental disorders and chronic physical diseases in developing and emerging countries: a meta-analysis. BMC Public Health 2019;19:304.

13 Park SJ, Hong S, Jang $\mathrm{H}$, et al. The prevalence of chronic physical diseases comorbid with depression among different sex and age groups in South Korea: a population-based study, 2007-2014. Psychiatry Investig 2018;15:370-5.

14 Patten SB. Long-term medical conditions and major depression in a Canadian population study at waves 1 and 2. J Affect Disord 2001;63:35-41.

15 Young JQ, Kline-Simon AH, Mordecai DJ, et al. Prevalence of behavioral health disorders and associated chronic disease burden in a commercially insured health system: findings of a case-control study. Gen Hosp Psychiatry 2015;37:101-8.

16 Ryu E, Chamberlain AM, Pendegraft RS, et al. Quantifying the impact of chronic conditions on a diagnosis of major depressive disorder in adults: a cohort study using linked electronic medical records. BMC Psychiatry 2016;16:114

17 Han K-M, Kim MS, Kim A, et al. Chronic medical conditions and metabolic syndrome as risk factors for incidence of major depressive disorder: a longitudinal study based on 4.7 million adults in South Korea. J Affect Disord 2019;257:486-94.

18 de Kloet ER, Joëls M, Holsboer F. Stress and the brain: from adaptation to disease. Nat Rev Neurosci 2005;6:463-75.

19 Yang L, Zhao Y, Wang Y, et al. The effects of psychological stress on depression. Curr Neuropharmacol 2015;13:494-504.

20 Birk JL, Kronish IM, Moise N, et al. Depression and multimorbidity: considering temporal characteristics of the associations between depression and multiple chronic diseases. Health Psychol 2019;38:802-11.

21 Gorman JM, Coplan JD. Comorbidity of depression and panic disorder. J Clin Psychiatry 1996;57:34-41.

22 Hölzel L, Härter M, Reese C, et al. Risk factors for chronic depression - a systematic review. J Affect Disord 2011;129:1-13.

23 Pollack MH. Comorbid anxiety and depression. J Clin Psychiatry 2005;66:22-9.

24 Konturek PC, Brzozowski T, Konturek SJ. Stress and the gut: pathophysiology, clinical consequences, diagnostic approach and treatment options. J Physiol Pharmacol 2011;62:591-9.

25 Fava GA, Tossani E. Prodromal stage of major depression. Early Interv Psychiatry 2007;1:9-18.

26 Kapfhammer H-P. Somatic symptoms in depression. Dialogues Clin Neurosci 2006;8:227-39.

27 Simon GE, VonKorff M, Piccinelli M, et al. An international study of the relation between somatic symptoms and depression. $N$ Engl $J$ Med 1999;341:1329-35.

28 McDonnall MC. The effects of developing a dual sensory loss on depression in older adults: a longitudinal study. J Aging Health 2009;21:1179-99.

29 Ohtsuki T, Inagaki M, Oikawa Y, et al. Multiple barriers against successful care provision for depressed patients in general internal medicine in a Japanese rural hospital: a cross-sectional study. BMC Psychiatry 2010;10:30. 
30 Ohtsuki T, Kodaka M, Sakai R, et al. Attitudes toward depression among Japanese non-psychiatric medical doctors: a cross-sectional study. BMC Res Notes 2012;5:441.

31 Gonzalez JS, Peyrot M, McCarl LA, et al. Depression and diabetes treatment nonadherence: a meta-analysis. Diabetes Care 2008;31:2398-403.

32 Chen AJ, Hwang V, Law PY, et al. Factors associated with noncompliance for diabetic retinopathy follow-up in an urban safety-net Hospital. Ophthalmic Epidemiol 2018:25:443-50.

33 Katon WJ, Lin EHB, Von Korff M, et al. Collaborative care for patients with depression and chronic illnesses. N Engl J Med 2010;363:2611-20.

34 Köhler-Forsberg O, Petersen L, Ishtiak-Ahmed K, et al. Medical diseases prior to first-time depression diagnosis and subsequent risk of admissions for depression: a nationwide study of 117,585 patients. J Affect Disord 2020;276:1030-7.

35 Dantzer R, O'Connor JC, Freund GG, et al. From inflammation to sickness and depression: when the immune system subjugates the brain. Nat Rev Neurosci 2008:9:46-56.
36 Iwata M, Ota KT, Duman RS. The inflammasome: pathways linking psychological stress, depression, and systemic illnesses. Brain Behav Immun 2013;31:105-14.

37 Raison CL, Capuron L, Miller AH. Cytokines sing the blues: inflammation and the pathogenesis of depression. Trends Immunol 2006;27:24-31.

38 Bair MJ, Robinson RL, Katon W, et al. Depression and pain comorbidity: a literature review. Arch Intern Med 2003;163:2433-45.

39 Baksa D, Gonda X, Juhasz G. Why are migraineurs more depressed? A review of the factors contributing to the comorbidity of migraine and depression. Neuropsychopharmacol Hung 2017;19:37-44.

40 Nuyen J, Volkers AC, Verhaak PFM, et al. Accuracy of diagnosing depression in primary care: the impact of chronic somatic and psychiatric co-morbidity. Psychol Med 2005;35:1185-95.

41 Hackett ML, Pickles K. Part I: frequency of depression after stroke: an updated systematic review and meta-analysis of observational studies. Int J Stroke 2014;9:1017-25.

42 Lu D, Andersson TML, Fall K, et al. Clinical diagnosis of mental disorders immediately before and after cancer diagnosis: a nationwide matched cohort study in Sweden. JAMA Oncol 2016;2:1188-96. 